\title{
Do We STILL NEed the 'Big Five'?
}

I. Van HerreweGhe ${ }^{1}$, K. Vermeylen ${ }^{2}$, S. Coppens ${ }^{1}$, M. Desmet ${ }^{3}$, L. VAn HeSE ${ }^{1}$, M. VAn de Velde ${ }^{1}$

${ }^{1}$ DEPT. OF ANESTHESIOLOGY, UNIVERSITY HOSPITAL LEUVEN, LEUVEN, BELGIUM 2 DEPT. OF ANESTHESIOLOGY, AZ TURNHOUT, TURNHOUT, BELGIUM

${ }^{3}$ DEPT. OF ANESTHESIOLOGY, AZ GROENINGE, KORTRIJK, BELGIUM

Background and aims

Interscalene (ISB), axillary- (ANB), transversus abdominis plane- (TAP), femoral- (FNB) and popliteal (POP) blocks, sometimes referred to as the "big five", have been popular for decades. Ultrasound guidance led to the development of new regional approaches. ${ }^{1}$ A survey was conducted to unveil shifts of these "popular" techniques.
Materials and methods

Together with the Belgian Association of Regional Anesthesia (BARA), two surveys were conducted (February to August 2017). One was sent to members of the BARA mailing list and questioned regional techniques for surgery. Another was sent to responders of the first survey to identify their postoperative pain management 5-10 years ago. Both surveys consisted out of a web-based questionnaire. McNemar's test was used to compare techniques.

\begin{tabular}{|c|c|c|c|c|c|c|}
\hline Region & Block & $\begin{array}{c}\text { Responders } \\
5-10 y \\
\text { (number) }\end{array}$ & $\begin{array}{c}\text { Responders } \\
5-10 \text { y (\%) }\end{array}$ & $\begin{array}{c}\text { Responders } \\
\text { Now } \\
\text { (number) }\end{array}$ & $\begin{array}{c}\text { Responders } \\
\text { Now (\%) }\end{array}$ & P-value \\
\hline Shoulder & ISB & 85 & $\mathbf{9 1 \%}$ & 81 & $\mathbf{8 7 \%}$ & 0,125 \\
\hline Elbow & SCB & 19 & $\mathbf{2 0 \%}$ & 45 & $\mathbf{4 8 \%}$ & $<0,001$ \\
\hline Elbow & ANB & 35 & $\mathbf{3 8 \%}$ & 24 & $\mathbf{2 6 \%}$ & 0,001 \\
\hline Hand & SCB & 6 & $\mathbf{6 \%}$ & 17 & $\mathbf{1 8 \%}$ & 0,001 \\
\hline Laparoscopic & TAP & 2 & $\mathbf{2 \%}$ & 12 & $\mathbf{1 3 \%}$ & 0,002 \\
\hline Abdominal & FICB & 3 & $\mathbf{3 \%}$ & 15 & $\mathbf{1 6 \%}$ & $<0,001$ \\
\hline Hip & FNB & 8 & $\mathbf{9 \%}$ & 8 & $\mathbf{9 \%}$ & $\mathbf{1}$ \\
\hline Knee & FNB & 26 & $\mathbf{2 8 \%}$ & 18 & $\mathbf{1 9 \%}$ & 0,008 \\
\hline Knee & ACB & 0 & $\mathbf{0 \%}$ & 16 & $\mathbf{1 7 \%}$ & - \\
\hline Knee & LIA & 3 & $\mathbf{3 \%}$ & 11 & $\mathbf{1 2 \%}$ & 0,008 \\
\hline Foot & POP & 63 & $\mathbf{6 8 \%}$ & 72 & $\mathbf{7 7 \%}$ & 0,004 \\
\hline
\end{tabular}

\section{References}

1. Marhofer, P., et al. "Fifteen years of ultrasound guidance in regional anaesthesia: part 1." British journal of anaesthesia104.5 (2010): 538-546.

Results

We received 220 and 136 (61,8\% of the first responders) answers. Among responders, the ISB remains the most popular for shoulder surgery. The supraclavicular block (SCB) gains interest for elbow and distal upper limb surgery, while there is a decrease in use of the ANB. TAP blocks are considerably more used in laparoscopic abdominal surgery than 5-10 years ago. For hip surgery, the fascia iliaca compartment block (FICB) is more frequently used than the FNB. Beside the frequently used FNB, the adductor canal block (ACB) and local infiltration analgesia (LIA) are remarkable new methods for knee surgery. The POP block is the ultimate golden standard for foot surgery.

\section{Conclusion}

The aim of this survey was to determine the most up-to-date peripheral nerve block technique in correlation with the surgical procedure. Prominent trends cannot be neglected. 